

\title{
The placenta as a barrier for toxic and essential elements in paired maternal and cord blood samples of South African delivering women
}

\author{
Cibele V. Rudge, ${ }^{a g}$ Halina B. Röllin, ${ }^{* b c d}$ Claudina M. Nogueira, ${ }^{e}$ Yngvar Thomassen, ${ }^{f}$ Marilza C. Rudge $^{a}$ \\ and Jon Ø. Odland ${ }^{g h}$
}

\author{
Received 24th February 2009, Accepted 20th May 2009 \\ First published as an Advance Article on the web 3rd June 2009 \\ DOI: $10.1039 / b 903805 a$
}

Environmental toxicants such as metals may be detrimental to foetus and infant development and health because of their physiological immaturity, opportunistic and differential exposures, and a longer lifetime over which disease, initiated during pregnancy and in early life, can develop. The placental mechanisms responsible for regulation of absorption and excretion of elements during pregnancy are not fully understood. The aim of this paper is to assess the correlation for selected toxic and essential elements in paired whole blood samples of delivering women and cord blood, as well as to evaluate the placental permeability for selected elements. Regression analyses used to assess this correlation in 62-paired samples of maternal and cord whole blood of delivering women show that the concentrations of mercury, lead, cobalt, arsenic and selenium in maternal and cord blood differed statistically. Lead, cobalt, arsenic and selenium appear to pass the placental barrier by a diffusion mechanism. It was also found that the mercury levels in cord blood were almost double those of the mother, suggesting that the foetus may act as a filter for the maternal mercury levels during pregnancy. Transplacental transfer for arsenic and cobalt was $80 \%$ and $45 \%$, respectively, suggesting that the placenta modulates the rate of transfer for these elements. Cadmium, manganese, copper and zinc levels did not show statistically significant correlations between two compartments (maternal versus cord whole blood). The study confirms that most of the toxic metals measured have an ability to cross the placental barrier.

\section{Introduction}

The developing foetus is particularly vulnerable to the toxic effects of metals. The placenta is an organ of transfer between mother and foetus through which all necessary nutrients are delivered. It also functions as a detoxifying barrier to prevent the passage of toxic substances to the foetus, including elements. ${ }^{1}$ If the latter is accomplished by binding of the element ions to the placenta, it may interfere with placental function, in particular with the transport of essential trace elements required for foetal growth and development. ${ }^{2,3}$

The transfer of all substances from foetus to mother and from mother to foetus depends primarily on the processes that permit or facilitate the transport of these substances, through the syncytiotrophoblast of the intact chorionic placenta. Transfer of substances from mother to foetus is accomplished first by transfer from the intervillous space into the syncytiotrophoblast. This process of transfer supplies the foetus with oxygen as well as nutrients and provides for elimination of metabolic waste products. Thus the chorionic villi and the intervillous space,

${ }^{a}$ São Paulo State University, UNESP, Brazil

${ }^{b}$ Medical Research Council, South Africa.E-mail: hrollin@mrc.ac.za; Fax. +2711642 6832; Tel: +27112746064

${ }^{c}$ University of Pretoria, South Africa

${ }^{d}$ University of the Witwatersrand, Johannesburg, South Africa

${ }^{e}$ National Institute for Occupational Health, Johannesburg, South Africa

${ }^{f}$ National Institute for Occupational Health, Oslo, Norway

${ }^{g}$ University of Tromso, Tromso, Norway

${ }^{h}$ University of Aarhus, Denmark together, function as lung, gastrointestinal tract and kidney for the foetus. Although this histological "barrier" separates the blood in the maternal and foetal circulations, it does not behave in an uniform manner as if it were a physical barrier. Throughout pregnancy, the syncytiotrophoblast actively or passively permits, facilitates, and adjusts the amount and rate of transfer of a wide range of substances to the foetus. ${ }^{4}$

To understand these mechanisms and determine the effectiveness of the human placenta as an organ of transfer, a number of factors must be considered, including substance concentration in the maternal plasma, the type of carrier protein and the area available for exchange. Furthermore, the physical properties of the tissue barrier and mode of transfer might influence the amount of substance metabolized by the placenta during the transfer. The area for exchange across the foetal capillaries in the placenta will determine the concentration of these substances in foetal blood. The rate of transfer is also guided by the presence of specific binding or carrier proteins and other ligands in maternal and/or the foetal circulations. Finally, the rate of the foetal blood flow through the villous capillaries will actively affect substance transfer. ${ }^{4}$

Even though the mechanisms of metal toxicity are mostly not known, it has been proposed that toxic element bioavailability, and hence toxicity, depends on the physiological form of the element before it enters the body to be transported within biological fluids and tissues. For example, studies with aluminium provide a very good example of how a detrimental metal ion can make use of the endogenous ligands, in its absorption, transport and availability to finally exert its toxic effects on target organs. 
Successful competition for the binding sites on different ligands, normally available to carry metal ions, which have similar properties, will be the target for such an interaction. ${ }^{5}$ Another example of this interaction is the metal binding protein metalloprotein-1(MT) which is expressed in the human syncytiotrophoblast and able to bind or sequester a host of metals including zinc, copper, lead and cadmium. ${ }^{4}$ The interaction of toxic elements with essential trace elements after environmental or occupational exposure plays an integral role in its toxicity. The toxicity of these elements may be increased or lessened by the metabolic status of the essential trace elements, which can be perturbed either through inborn genetic defects, or upon exposure to various environmental influences. ${ }^{6,7}$

It has been shown that 'chronic low-level exposure to lead during early development in children can result in behavioral alterations in the absence of overt toxicity'. ${ }^{8}$ This perturbation of the function of the central nervous system may be due to deficiencies in essential elements, resulting from lead-induced impairment of mineral availability and/or an increased sensitivity to lead in the absence of adequate levels of essential trace metals such as zinc. Zinc is also thought to reduce cadmiuminduced ultra-structural alteration of the liver.9,10 Interactions between toxic and essential elements have been reported; it is well documented for lead and iron in anaemia due to iron deficiency. Similar interactions have been reported for mercury and iron, arsenic and selenium, iodine and selenium, cadmium and zinc, aluminium with copper and zinc. ${ }^{11-14}$ Furthermore, zinc, copper and selenium are essential for reproductive processes. $^{15}$

Therefore, the ability of the placenta to transfer nutrients and toxicants alike is of concern in relation to foetal development and health. ${ }^{16}$ In most cases, the same processes that aid transport of nutrients through the placenta, may also act as the pathways for toxic elements, especially if these have chemical similarities with the nutrient metabolites, or simply because of passive diffusion. It is also understood that in some cases, the placenta acts as a barrier by preferentially concentrating and retaining specific toxicants, thus acting as a detoxicant and thereby reducing, to some degree, the toxic effect on the foetus. ${ }^{17}$

The placental mechanisms responsible for the regulation of elemental concentrations, both in the pregnant woman and the developing foetus, are not fully understood and need further investigation. Scientific evidence shows that foetus and infants are more affected than adults by a variety of environmental toxicants due to their physiological immaturity, opportunistic and differential exposures, and a longer lifetime over which disease, initiated during pregnancy and in early life, can develop. ${ }^{18}$ A number of studies, by Odland et al., performed under the umbrella of the Arctic Monitoring and Assessment Programme (AMAP) project in the Arctic region, measured 16 elements (both essential and toxic) in maternal and cord blood and in placental tissues, in different populations residing in the Arctic. These studies quantified the ability of elements to transfer through the placenta and evaluated/predicted their potential to impact on foetal development. ${ }^{19-21}$ These investigations showed maternal age and body mass index (BMI) to be positive predictors of birth weight. They identified cigarette smoking and lead exposure as negative determinants in terms of established evidence and recognized confounders, including maternal genetic factors, socio-economic status, socio-political change, life-style issues, prenatal care and nutrition. ${ }^{22}$ An important finding of these studies was the evidence that the placental concentrations of toxic elements may serve as an index of exposure and of nutritional intake and status for selected essential microelements. ${ }^{23}$ The authors concluded that inter-element relationships and groupings of the measured elements may constitute a scientific base for the use of placental composition in environmental monitoring and epidemiological studies. ${ }^{19}$

These and other similar data originate predominantly from investigations carried out in the Northern Hemisphere. In contrast, in the Southern Hemisphere there has been limited research to assess levels of toxicants, to estimate human exposure and risks, and to evaluate spatial and temporal trends. Furthermore, women and children (who are the largest segment of these societies) are particularly affected, and considered to be most vulnerable. The confounding factors mentioned previously differ in the Southern Hemisphere, and the detrimental effects of toxicants may be further potentiated by the climatic, socioeconomic and political conditions, rapid urbanization, poor health status and nutrition, high rate of unemployment and high prevalence of disease (TB, HIV/Aids, malaria) among populations in this region.

This paper reports on the correlation between mother and cord blood levels of toxic and essential elements, in paired samples of blood of delivering women in South Africa, as an indicator of placental barrier, and possible exposure during pregnancy.

The findings reported here form part of the pilot study titled "Levels of Persistent Toxic Substances (PTS) in maternal and umbilical cord blood from selected areas of South Africa"

\section{Materials and methods}

The results reported in this paper were obtained from sixty-two pairs of randomly selected mothers and newborns recruited from patients presenting for delivery at hospitals in South Africa. Whole blood was drawn by venous puncture from the mother before delivery, using the sterile Vacutainer disposable system; umbilical cord blood was collected post-partum by a nursing sister using a syringe, and stored at $-20{ }^{\circ} \mathrm{C}$ until analysed. Contamination-free vessels and procedures were used throughout. Samples of maternal and cord whole blood were digested and analyzed for total concentrations of cadmium (Cd), mercury $(\mathrm{Hg})$, lead $(\mathrm{Pb})$, manganese $(\mathrm{Mn})$, cobalt $(\mathrm{Co})$, copper $(\mathrm{Cu})$, zinc $(\mathrm{Zn})$, arsenic (As) and selenium (Se) by inductively coupled plasma-mass spectrometry (ICP-MS). Seronorm ${ }^{\mathrm{TM}}$ Trace Elements (Sero LTD., Billingstad, Norway) human whole blood quality control materials were used for quality assurance of all element measurements; after every ten blood samples analyzed, a quality control sample at two different concentration levels was also analyzed. For the purpose of this paper, the researchers extracted delivery records from the patient hospital files; these included date of the delivery, weight and length of the baby, caput, Naegele term, Apgar score, gestational age, as well as congenital malformations, birth complications and outcomes as per comments of doctor or sister present at delivery. Details of data collection and analytical procedures are described elsewhere. $^{24}$ 


\section{Ethical considerations}

Ethical approval of the study protocol was obtained from the Committee for Research on Human Subjects of the University of the Witwatersrand, Johannesburg (Clearance Certificate Protocol Number M040314). Informed written consent was obtained from each participant prior to commencement of the study.

\section{Statistical analysis}

Statistical analyses were conducted using the statistical STATA package, version 10 (Stata10 2007). ${ }^{25}$ Descriptive statistics were calculated for birth outcome characteristics and element levels. A linear regression model was used to correlate levels of measured elements between paired maternal and cord whole blood samples.

\section{Results}

The study found that the mean age of the sixty-two delivering women included in this paper was 24.7 (SD 6.2) years. Only 8.7\% of women were nulliparous and the majority $(52.3 \%)$ was primiparous (range 1 to 6 ). Eleven percent of women reported to have had spontaneous abortion previously. Only three mothers in the group reported smoking during pregnancy (less than 10 cigarettes per day).

Details of birth outcomes are summarized in Table 1. The mean gestational age was 38.9 (SD 2.3) weeks. From sixty-two deliveries, $54(87 \%)$ were vaginal and $8(13 \%)$ were by Caesarean section. The mean birth weight was found to be 3104 (SD 490) $\mathrm{g}$ and the mean length of the babies was 49.5 (SD 3.6) $\mathrm{cm}$ with the mean head circumference of $34(\mathrm{SD} 2) \mathrm{cm}$. The gender split of the newborns was as follows: $29(47 \%)$ were female and $33(53 \%)$ were male. The Apgar score was normal in most cases with only two cases of Apgar less than 7 for one minute. Only one case of congenital malformation (clubfoot) was observed at birth.

The concentrations and descriptive statistics for each metal measured in paired maternal and umbilical cord bloods are shown in Table 2 and Table 3 respectively. In a few cases, the concentration of elements measured was equal or below the detection limit (LOD) of the method, and for statistical purposes, these concentrations were set at $0.5 \times$ LOD.

Table 1 Characteristics of birth outcomes $(n=62)$

\begin{tabular}{lcl}
\hline Birth outcomes & Mean (SD) & $\%$ \\
\hline Maternal age/years & $24.7(6.2)$ & \\
Gestational age/weeks & $38.9(2.4)$ & 87 \\
Delivery methods: & 54 & 13 \\
Vaginal & 8 & \\
Caesarean Section & $3104(490)$ & \\
Birth weight/g & $49.5(3.6)$ & \\
Birth length/cm & $34(1.9)$ & 53 \\
Head circumference/cm & 62 & \\
Baby sex $(n)$ & 29 & \\
Female & 33 & \\
Male & 2 & \\
Apgar score $<7$ & \multicolumn{2}{l}{} \\
1 min & & \\
5 min & & \\
\end{tabular}

Table 2 Concentrations of $\mathrm{Cd}, \mathrm{Hg}, \mathrm{Pb}, \mathrm{Mn}, \mathrm{Co}, \mathrm{Cu}, \mathrm{Zn}, \mathrm{Se}, \mathrm{As}$ in maternal blood $/ \mu \mathrm{g} \mathrm{L}{ }^{-1}$

\begin{tabular}{lccc}
\hline Metals/ $\mu \mathrm{g} \mathrm{L}^{-1}$ & Median $n=62$ & Range & $\mathrm{IQR}^{a}$ \\
\hline $\mathrm{Cd}$ & 0.15 & $0.04-0.89$ & $0.10-0.20$ \\
$\mathrm{Hg}$ & 0.65 & $0.1-8.8$ & $0.34-1.20$ \\
$\mathrm{~Pb}$ & 23 & $6-161$ & $14.6-31.0$ \\
$\mathrm{Mn}$ & 16.8 & $8.7-63.5$ & $13.8-21.6$ \\
$\mathrm{Co}$ & 0.60 & $0.21-15.3$ & $0.41-0.98$ \\
$\mathrm{Cu}$ & 1730 & $1200-2420$ & $1520-1900$ \\
$\mathrm{Zn}$ & 6290 & $3000-11400$ & $5400-7130$ \\
$\mathrm{As}$ & 0.57 & $0.08-3.12$ & $0.32-0.91$ \\
$\mathrm{Se}$ & 104 & $63-203$ & $86-131$ \\
${ }^{a} \mathrm{IQR}=$ inter-quartile range (25-75). & & \\
\hline
\end{tabular}

Table 3 Concentrations of $\mathrm{Cd}, \mathrm{Hg}, \mathrm{Pb}, \mathrm{Mn}, \mathrm{Co}, \mathrm{Cu}, \mathrm{Zn}, \mathrm{Se}, \mathrm{As}$ in cord blood/ $\mu \mathrm{g} \mathrm{L}^{-1}$

\begin{tabular}{lccc}
\hline Metals $/ \mu \mathrm{g} \mathrm{L}^{-1}$ & Median $n=62$ & Range & $\mathrm{IQR}^{a}$ \\
\hline $\mathrm{Cd}$ & 0.02 & $0-0.32$ & $0.01-0.21$ \\
$\mathrm{Hg}$ & 1.2 & $0.1-9.7$ & $0.56-2.16$ \\
$\mathrm{~Pb}$ & 15.4 & $1.4-95.1$ & $10.2-23.4$ \\
$\mathrm{Mn}$ & 34.9 & $7.2-80.7$ & $27.3-45.3$ \\
$\mathrm{Co}$ & 0.27 & $0.03-9.4$ & $0.17-0.41$ \\
$\mathrm{Cu}$ & 657 & $384-1410$ & $590-704$ \\
$\mathrm{Zn}$ & 2548 & $1560-4738$ & $2160-2920$ \\
$\mathrm{As}$ & 0.46 & $0.04-2.84$ & $0.32-0.83$ \\
$\mathrm{Se}$ & 111 & $50-202$ & $93-145$ \\
${ }^{a} \mathrm{IQR}=$ inter-quartile range $(25-75)$. & & \\
\hline
\end{tabular}

Fig. 1-5 indicate the results of regression analyses used to assess the linear correlation between levels of mercury, lead, cobalt, arsenic and selenium in paired maternal blood (right hand side) and cord blood (left hand side).

The median $\mathrm{Cd}$ level in maternal $(\mathrm{CdM})$ and cord blood (CdCB) was found to be $0.15 \mu \mathrm{g} \mathrm{L}^{-1}$ and $0.02 \mu \mathrm{g} \mathrm{L}^{-1}$ respectively. No correlation between maternal and cord blood for cadmium concentrations was found ( $\mathrm{r}-\mathrm{sq}=2.4 \%, p=0.35$ ).

The median $\mathrm{Hg}$ concentration for maternal blood $(\mathrm{HgM})$ was found to be $0.65 \mu \mathrm{g} \mathrm{L}^{-1}$ as compared to the median mercury cord blood level ( $\mathrm{HgCB})$ of $1.22 \mu \mathrm{g} \mathrm{L}^{-1}$. This correlation was highly significant (r-sq 76.9\%, $p<0.0001$ ); see Fig. 1.

The median $\mathrm{Pb}$ concentration for maternal blood $(\mathrm{PbM})$ was found to be $23 \mu \mathrm{g} \mathrm{L}^{-1}$ and the median $\mathrm{Pb}$ cord blood concentration $(\mathrm{PbCB})$ was $15 \mu \mathrm{g} \mathrm{L}^{-1}$. This correlation was also highly significant $(\mathrm{r}-\mathrm{sq}=83.3 \%, p<0.0001)$; see Fig. 2 .

The median Mn concentration for maternal blood (MnM) was found to be $16.8 \mu \mathrm{g} \mathrm{L}^{-1}$ with the median manganese cord blood concentration $(\mathrm{MnCB})$ of $34.9 \mu \mathrm{g} \mathrm{L}^{-1}$. However, there was no correlation between maternal and cord blood manganese levels $(\mathrm{r}-\mathrm{sq}=3.9 \%, p=0.13)$.

The median Co concentration for maternal blood (CoM) was found to be $0.60 \mu \mathrm{g} \mathrm{L}^{-1}$; the median cobalt cord blood concentration $(\mathrm{CoCB})$ was $0.27 \mu \mathrm{g} \mathrm{L}^{-1}$ with a highly significant correlation between maternal and cord blood $(\mathrm{r}-\mathrm{sq}=95.8 \%, p<$ 0.0001); see Fig. 3.

The median $\mathrm{Cu}$ concentration for maternal blood $(\mathrm{CuM})$ was found to be $1730 \mu \mathrm{g} \mathrm{L}^{-1}$ as compared to the median cord blood 

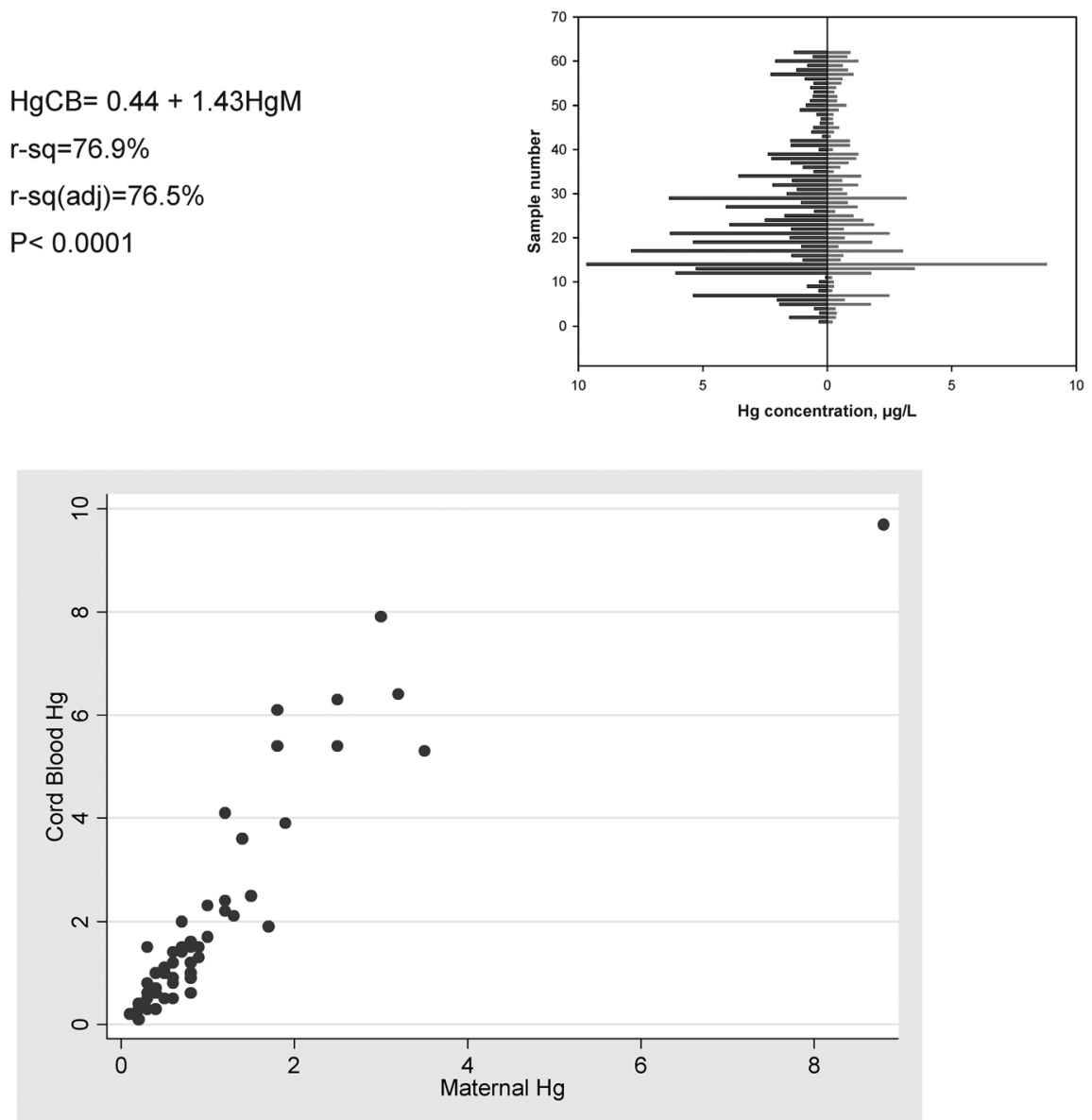

Fig. 1 Mercury concentration: correlation between maternal and cord blood. Left cord blood (HgCB); right maternal blood (HgM).

concentration $(\mathrm{CuCB})$ of $657 \mu \mathrm{g} \mathrm{\textrm {L } ^ { - 1 }}$. There was no correlation between maternal and cord blood for copper levels $(\mathrm{r}-\mathrm{sq}=0.0 \%$, $p=0.96$ ).

The median $\mathrm{Zn}$ concentration for maternal blood $(\mathrm{ZnM})$ was found to be $6830 \mu \mathrm{g} \mathrm{L}^{-1}$ and the median cord blood concentration $(\mathrm{ZnCB})$ was $2550 \mu \mathrm{g} \mathrm{L}^{-1}$. There was no correlation between maternal and cord blood for zinc levels $(\mathrm{r}-\mathrm{sq}=0.0 \%, p=0.99)$.

The median As concentration for maternal blood (AsM) was found to be $0.57 \mu \mathrm{g} \mathrm{L}^{-1}$ and the median As cord blood concentration (AsCB) was $0.46 \mu \mathrm{g} \mathrm{L}^{-1}$. There was a high correlation between maternal and cord blood arsenic levels $(\mathrm{r}-\mathrm{sq}=85.7 \%, p$ $<0.0001$ ); see Fig. 4.

The median Se concentration for maternal (SeM) and cord blood (SeCB) was found to be $104 \mu \mathrm{g} \mathrm{L}^{-1}$ and $111 \mu \mathrm{g} \mathrm{L}^{-1}$, respectively, with significant correlation between selenium in maternal and cord blood ( $\mathrm{r}-\mathrm{sq}=60.3 \%, p<0.0001)$; see Fig. 5.

Linear equations for each element are shown in each of the figures.

When comparing concentration of elements in cord blood in different maternal age groups, highest median mercury cord blood concentration of $1.4 \mu \mathrm{g} \mathrm{L}^{-1}$ was in the 20-25 year age group; and the highest median lead cord blood concentration of $23 \mu \mathrm{g} \mathrm{L}^{-1}$ was found in the group older than 30 years of age; these results were not statistically significant. The study found significant correlation between selenium and mercury in maternal blood, in the 20-25 year age group $(p<0.001)$.

\section{Discussion}

This study quantified the levels of toxic and essential elements in sixty-two paired samples of maternal and cord blood, and assessed the statistical significance of the correlation for metals between each individual mother and child pair. This allowed for the assessment of the detoxifying ability of the placenta, and/or prediction of placental barrier for each element.

Regression analyses showed that the correlation between maternal and cord blood for mercury, lead, cobalt, arsenic and selenium was highly significant indicating that the foetal body burden reflects the maternal exposure. ${ }^{26}$ However, no correlation was found for cadmium, manganese, copper or zinc.

The study found different levels of total mercury in maternal and cord bloods, with a median of $0.65 \mu \mathrm{g} \mathrm{L}^{-1}$ and $1.2 \mu \mathrm{g} \mathrm{L}^{-1}$, respectively. These levels indicate the absorbed dose as well as the amount available systemically. This is of concern, as the methyl mercury fraction (usually $>98 \%$ of total mercury) binds to haemoglobin and, in particular, has a high affinity for foetal haemoglobin; hence cord blood mercury in its methylated form passes easily through the placenta. ${ }^{27,28}$ This specific mechanism 

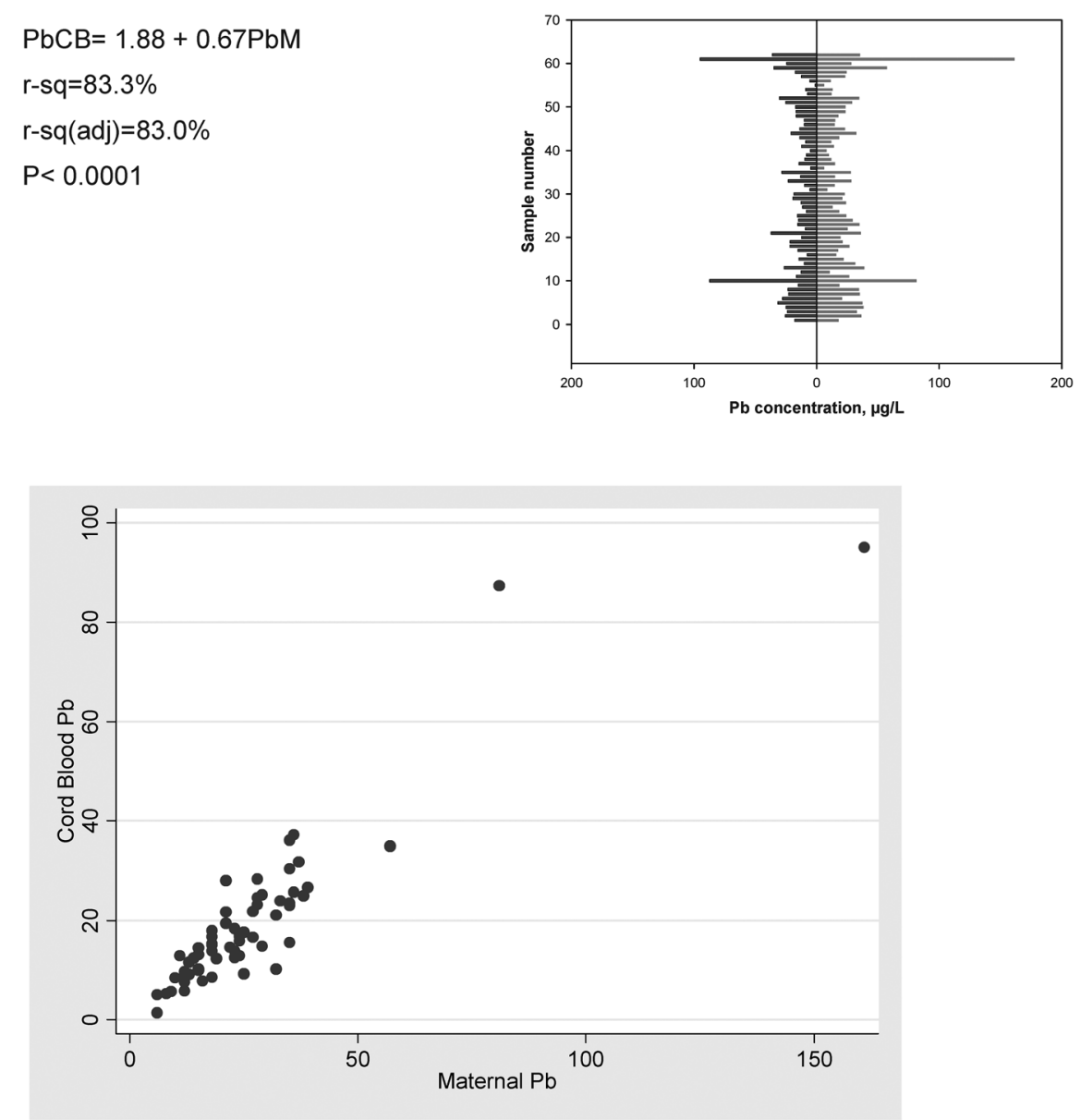

Fig. 2 Lead concentration: correlation between maternal and cord blood. Left cord blood ( $\mathrm{PbCB}$ ); right maternal blood (PbM).

results in a higher concentration of mercury in cord blood, when compared with maternal blood, as shown in this and other studies. ${ }^{29,30}$ In our study, $7.5 \%$ of cord bloods had mercury concentrations above $5.8 \mu \mathrm{g} \mathrm{L}^{-1}$, a level associated with loss of IQ. ${ }^{31}$ Follow-up studies of a cohort of children, by Faroe Island researchers, found significant dose-related, adverse associations between pre-natal exposure to mercury and intellectual performance indicators such as memory, attenuation, language, and visual-spatial perception. ${ }^{32}$ Furthermore, a recent study by Jedrychowski et al. suggests the cut-off value for mercury for newborns to be $0.90 \mu \mathrm{g} \mathrm{L}^{-1}{ }^{33}$ In the present study, $25 \%$ of cord bloods exceeded this suggested concentration. The ratio between cord and maternal blood was calculated to be 1.85 , similar to the value of 1.7 reported by Vahter et al. ${ }^{34}$ These findings are in agreement with other studies and confirm that the placenta does not act as a protective barrier against the transfer of mercury, from mother to foetus. ${ }^{35,26}$

Speciation of mercury in maternal and cord blood and placentas by Ask et al. show that methyl mercury species concentrations are higher in the umbilical cord blood than in maternal blood, and the methyl mercury concentrations in placentas are twice of those in maternal blood, indicating retention of methyl mercury in placenta tissue. ${ }^{36}$ The majority of studies associates elevated concentrations of mercury with consumption of contaminated fish and marine products. ${ }^{37}$ In our study, dietary intake of fish was found to be low. When comparing our findings with others in the Southern Hemisphere, mercury levels in maternal blood were comparable to those reported in women with low fish consumption from the Amazon, Brazil. ${ }^{38}$ This higher foetal cord blood concentration, compared to maternal blood, provides an example of transport and sequestration of this metal. It may indicate that mercury is transported actively from maternal to foetal plasma by a facilitated diffusion mechanism. ${ }^{4}$

Our study found a significant correlation for lead between maternal and the corresponding cord bloods, although low in both, confirming that lead easily crosses the placental barrier. Nevertheless, these findings should be interpreted with caution, as recent research suggests that there is no safe level of lead in foetus and young children, and even low concentrations can have negative neurotoxic effects. ${ }^{39-42}$ Other studies have also shown a significant correlation between maternal and cord blood lead at higher concentrations. ${ }^{43-46}$ In our study, only one case of elevated lead level (above the action level of $100 \mu \mathrm{g} \mathrm{L}^{-1}$ ) was found in a maternal and cord blood pair $-161 \mu \mathrm{g} \mathrm{L}^{-1}$ and $95 \mu \mathrm{g} \mathrm{L}^{-1}$, respectively. The lead concentrations found in our study were lower that those reported in other developing countries.

Another toxic element that showed significant correlation between maternal and cord blood was arsenic. In the South 

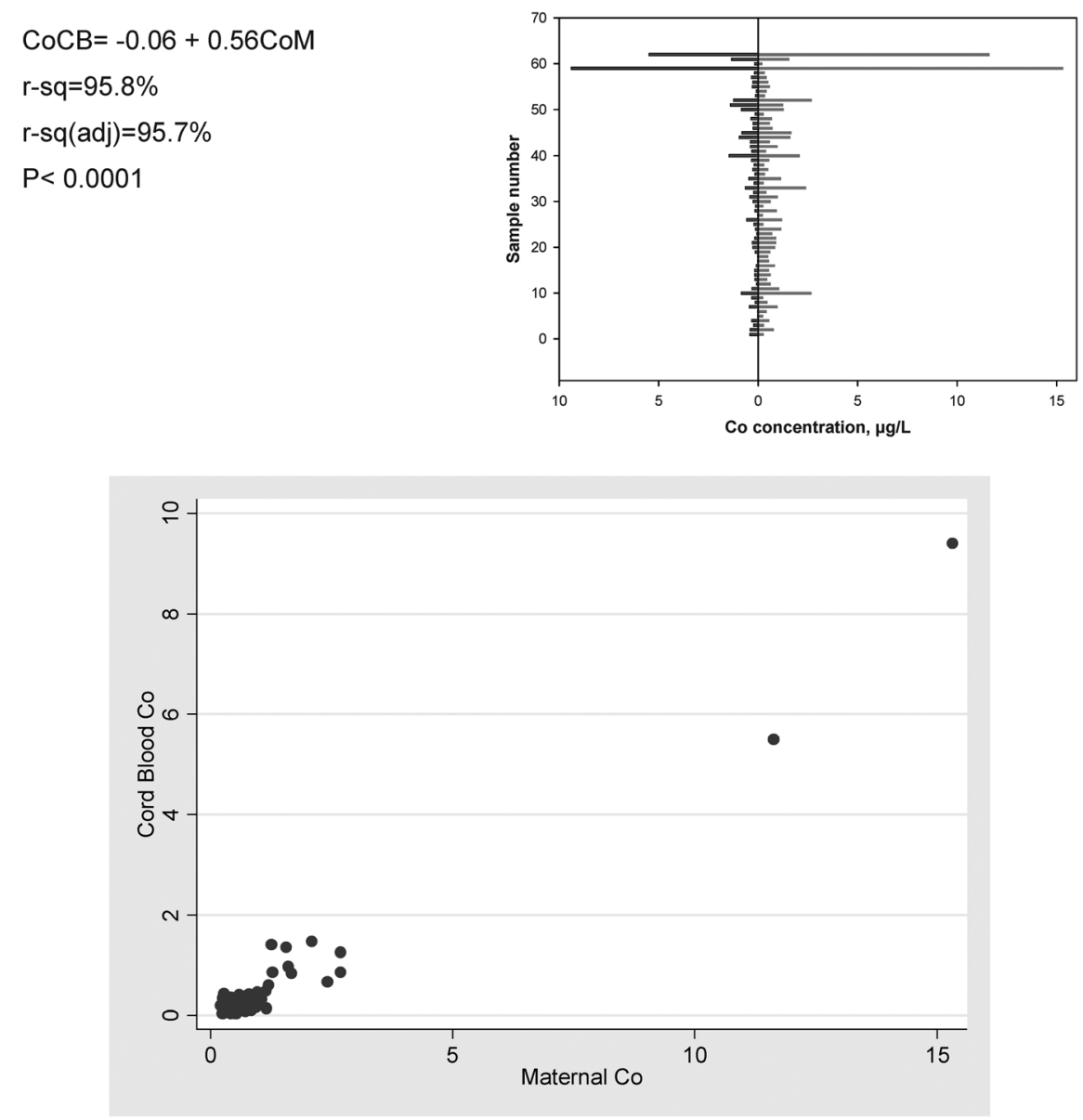

Fig. 3 Cobalt concentration: correlation between maternal and cord blood. Left cord blood (CoCB); right maternal blood (CoM).

African context, the sources of arsenic are likely to be mining activities, agriculture and food. More research is needed to confirm this. Studies elsewhere, suggest that most of the total arsenic measured in food is largely in its organic form (especially in fish products) and high levels of inorganic arsenic are not commonly found. The differences in cadmium concentration between maternal and cord blood were not statistically significant and much lower than in most of the reported studies, probably due to the low prevalence of smoking. Other studies also reported no significant correlation for cadmium between maternal and cord blood cadmium concentration. ${ }^{46}$

Of the elements measured, manganese, cobalt, copper, selenium and zinc are essential elements, but toxic at high concentrations. The main source of these elements is food. However, nutritional status can be both a confounder and an effect modifier of the association between elements and toxicity. In the case of manganese, both deficiency and excess may have detrimental health effects. As with mercury and lead, the brain is the critical target organ for manganese. Our study found no significant statistical correlation between manganese levels in paired maternal and cord blood, but mean concentrations of manganese in both compartments were found to be higher than the upper limit of $14 \mu \mathrm{g} \mathrm{L}^{-1}$, (ATSDR, 2000). ${ }^{47}$ At present, the risk of manganese-induced neurotoxicity during pre- and postnatal brain development, is not fully researched or understood. ${ }^{48}$ The association between manganese uptake during pregnancy and early psychomotor development of children was reported. ${ }^{49}$ Animal experimentation also show that neonatal rodents are at increased risk for manganese-induced neurotoxicity. ${ }^{50,51}$ In contrast, Takeda et al. showed that the higher manganese concentrations are needed during foetal rat brain development, suggesting that a sufficient manganese supply is critical. ${ }^{52}$

Copper is an essential trace element for the enzyme systems of catalase, superoxide dismutase and cytochrome oxidase, and its deficiency can lead to a variety of nutritional and vascular disorders. The newborn is dependent on stored copper, which may not be adequate in premature infants. The ratio of newborn to adult liver copper levels is about $4: 15 .{ }^{53}$ This study found the levels of copper to be on average lower in cord blood, with no significant correlation between maternal and cord blood. Interestingly, our results showed higher concentrations of copper in maternal whole blood when compared to those reported by AlSaleh et al., but a similar ratio between cord and maternal blood levels. Similarly, no correlation was found for zinc between maternal and cord concentrations. ${ }^{54}$

Cobalt and selenium show a high correlation between maternal and cord blood and both were found to be within normal levels. As with manganese, selenium excess and deficiency may be detrimental to health, with deficiency being reported to impair foetal development in animals. ${ }^{55}$ The levels of 

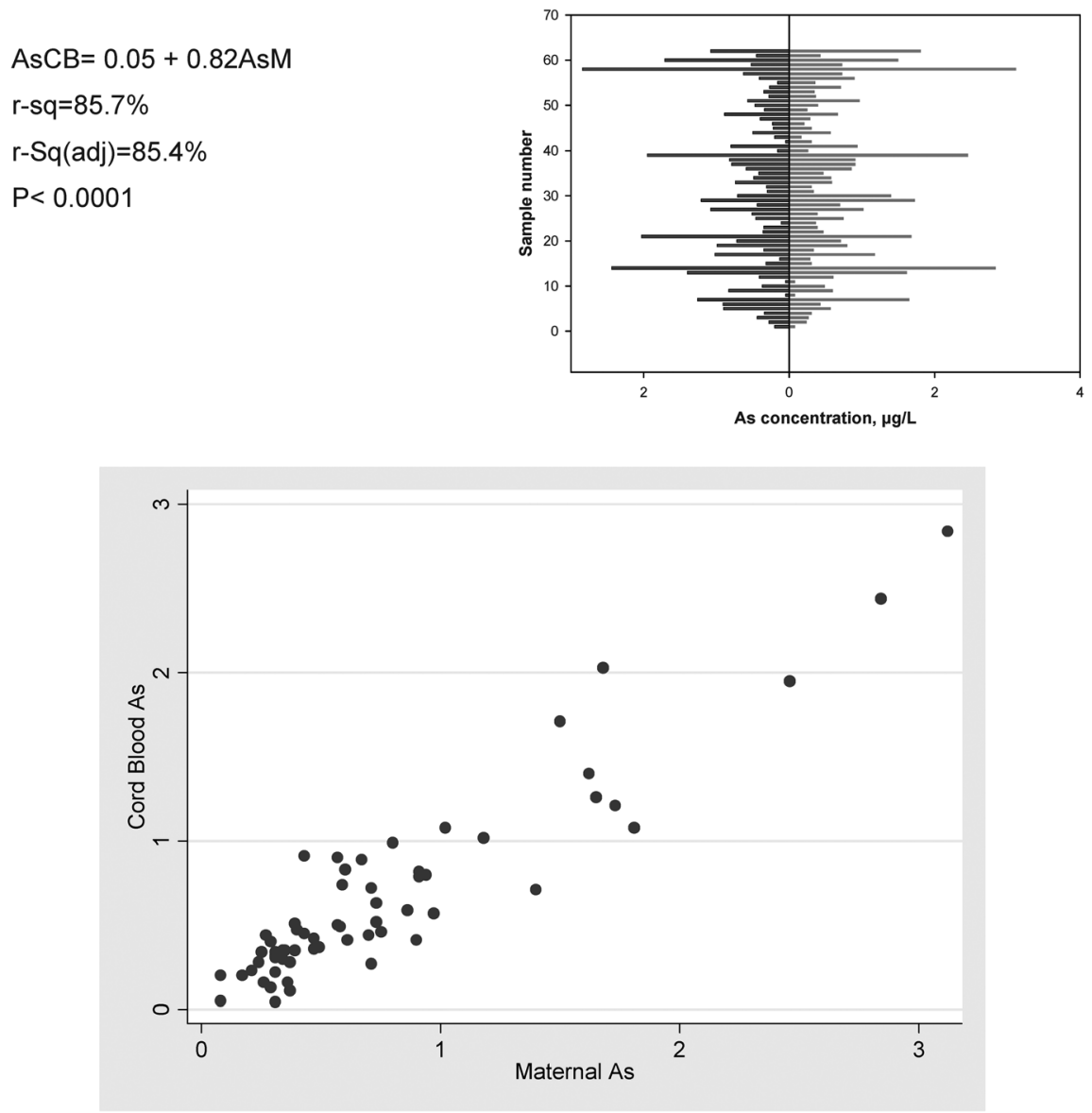

Fig. 4 Arsenic concentration: correlation between maternal and cord blood. Left cord blood (AsCB); right maternal blood (AsM).

selenium in our study were very similar to those reported by AlSaleh in the maternal population of Kuwait. ${ }^{54}$ Furthermore, selenium is an essential element and is thought to lower mercury toxicity, but its underlying mechanism is not fully understood. Our study found a correlation between selenium and mercury levels in maternal blood in spite of low fish consumption in the study population. Similar findings have been reported by other researchers, suggesting that this interaction may be independent of fish consumption. ${ }^{56,57}$ Thus, more research is needed to assess the role of selenium in mercury toxicity.

\section{Conclusions}

The study confirms that most of the toxic metals have an ability to cross the placental barrier. All subjects in this group were from lower socioeconomic circumstances and none reported previous or current occupational exposures to chemicals, which seems to indicate that the contaminants present in water, food, soil, and air are a primary source of toxins. A possible placental threshold mechanism for cadmium could not be demonstrated in our study. The mercury and manganese levels in cord blood were almost double those of the mothers, indicating high placental permeability between both compartments. The almost free passage of lead from mother to foetus is of clinical relevance, as lead is always toxic, irrespective of concentration. ${ }^{38}$
A limitation of this study is that the levels of copper and zinc were measured in whole blood, thus not allowing for direct clinical comparison with other studies that measured these elements in serum or plasma. Another constraint was the small sample size of the study population, hence the findings cannot be considered representative of the South African pregnant population. Our findings highlight the need for a more comprehensive study that will address these issues.

\section{Acknowledgements}

The authors thank the University of Tromsø, Norway; the University of Aarhus, Denmark; the Arctic Monitoring and Assessment Programme (AMAP), Oslo, Norway; The Nordic Council of Ministers, Copenhagen, Denmark; and the SA Medical Research Council for financial support of this study.

We deeply thank all mothers who kindly participated in this survey and staff of maternity wards in provincial hospitals of South Africa. We also thank colleagues from the SA Medical Research Council: Mrs Mirriam Mogotsi for her expert assistance in data and sample collection and research intern Mrs Kebitsamang Moiloa for her assistance in administration of questionnaires. We thank staff of the Analytical Services laboratory of the $\mathrm{NIOH}$, Johannesburg for processing of the 


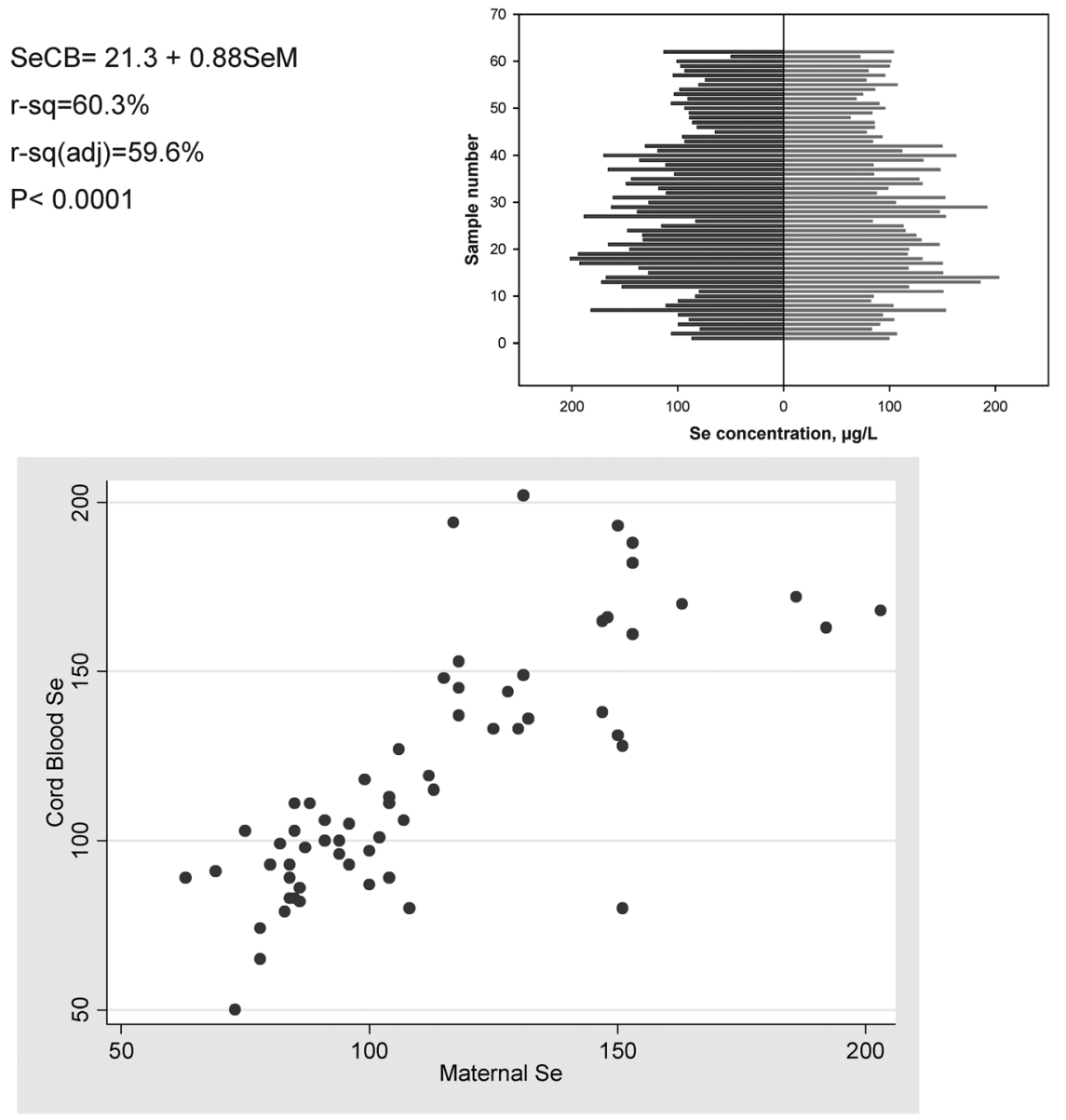

Fig. 5 Selenium concentration: correlation between maternal and cord blood. Left cord blood (SeCB); right maternal blood (SeM).

biological samples. We thank Natalya Romanova for statistical advice.

The first author (C. Rudge) is recipient of a doctoral PDEE fellowship from the Brazilian Federal Agency for Graduate Studies (CAPES, Ministry of Education).

\section{References}

1 K. Osman, A. Akesson, M. Berglund, K. Bremme, A. Schutz, K. Ask and M. Vahter, Clin. Biochem., 2000, 33, 131-138.

2 P. M. Kuhnert, B. R. Kuhnert, P. Erhard, W. T. Brashear, S. L. Groh-Wargo and S. Webster, Am. JObstet. Gynecol., 1987, 157, $1241-1246$.

3 WHO/FAO/IAEA, Report on trace elements in human nutrition and human health., World Health Organization, Geneva, 1996.

4 F. G. Cunningham and J. W. Williams, Williams Obstetrics, 20th edn., Prentice-Hall, London, 1997.

5 H. B. Röllin and C. M. Nogueira, Eur. J. Clin. Chem. Clin. Biochem., 1997, 35, 215-222.

6 H. B. Röllin, P. Theodorou and T. A. Kilroe-Smith, South African Journal of Science, 1993, 89, 246-249.

7 M. Gulumian, R. D. Hancock and H. B. Röllin, in Bioinorganic Chemistry. Handbook on Metal Ligand Interactions in Biological Fluids, ed. M. D. Ed. Guy Berthon, Inc, Toulouse, France, Editon edn., 1995, vol. 1, pp 117-129.

8 G. D. Miller, T. F. Massaro and E. J. Massaro, Neurotoxicology, 1990, 11, 99-119.
9 H. G. Petering, H. Choudhury and K. L. Stemmer, Environ. Health Perspect., 1979, 28, 97-106.

10 K. Nakamura, S. Nishiyama, T. Takata, E. Suzuki, Y. Sugiura, T. Mizukoshi, B. Y. Chao and H. Enzan, Ind. Health, 1982, 20, 347-355.

11 R. A. Goyer, Annu. Rev. Nutr., 1997, 17, 37-50.

12 B. Elsenhans, W. Forth and E. Richter, Arch. Toxicol., 1991, 65, 429432.

13 A. S. Prasad, J. Am. Coll. Nutr., 1988, 7, 377-384.

14 H. B. Röllin, P. Theodorou and T. A. Kilroe-Smith, Br. J. Ind. Med., 1991, 48, 389-391.

15 R. S. Bedwal and A. Bahuguna, Burghäuser Verlag Basel, 1994, 626.

16 G. V. Iyengar and A. Rapp, Sci. Total Environ., 2001, 280, 207-219.

17 R. A. Goyer, Environ. Health Perspect., 1990, 89, 101-105.

18 F. P. Perera, W. Jedrychowski, V. Rauh and R. M. Whyatt, Environ. Health Perspect., 1999, 107(Suppl 3), 451-460.

19 J. Ø. Odland, E. Nieboer, N. Romanova, Y. Thomassen, D. Hofoss and E. Lund, J. Environ. Monit., 2001, 3, 177-184.

20 J. Ø. Odland, E. Nieboer, N. Romanova, D. Hofoss and Y. Thomassen, J. Environ. Monit., 2003a, 5(1), 166-174.

21 J. Ø. Odland, E. Nieboer, N. Romanova and Y. Thomassen, Int. J. Circumpolar. Health, 2004, 63, 169-187.

22 A. Vaktskjold, E. E. Paulsen, L. Talykova, E. Nieboer and J. O. Odland, Int. J. Circumpolar. Health, 2004, 63, 39-60.

23 J. Ø. Odland, B. Deutch, J. C. Hansen and I. C. Burkow, Acta Paediatr., 2003b, 92, 1255-1266.

24 H. B. Röllin, C. V. C. Rudge, Y. Thomassen, A. Mathee and J. Ø. Odland, J. Environ. Monit., 2009, 11, 618-627.

25 Stata10, in College Station TX, ed. StataCorpLP, Editon edn., 2007.

26 R. Sikorski, T. Paszkowski, P. Slawinski, J. Szkoda, J. Zmudzki and S. Skawinski, Ginekol. Pol., 1989, 60, 151-155. 
27 B. J. Kelman, B. K. Walter and L. B. Sasser, J. Toxicol. Environ Health, 1982, 1982, 10(2), 191-200.

28 H. Tsuchiya, K. Mitani, K. Kodama and T. Nakata, Arch. Environ. Health, 1984, 39(1), 11-17.

29 A. H. Stern and A. E. Smith, Environ. Health Perspect, .2003, 111 $1465-1470$

30 K. A. Björnberg, M. Vahter, K. Petersson-Grawe, A. Glynn, S. Cnattingius, P. O. Darnerud, S. Atuma, M. Aune, W. Becker and M. Berglund, Environ. Health Perspect., 2003, 111, 637-641.

31 L. Trasande, P. J. Landrigan and C. Schechter, Environ. Health Perspect., 2005, 113, 590-596.

32 P. Grandjean, P. Weihe, R. F. White, F. Debes, S. Araki, K. Murata, N. Sørensen, D. Dahl, K. Yokoyama and P. J. Jørgensen, Neurotoxicol. Teratol., 1997, 19, 417-428.

33 W. Jedrychowski, J. Jankowski, E. Flak, A. Skarupa, E. Mroz, E. Sochacka-Tatara, I. Lisowska-Miszczyk, A. Szpanowska-Wohn, V. Rauh, Z. Skolicki, I. Kaim and F. Perera, Ann. Epidemiol., 2006, 16, 439-447.

34 M. Vahter, A. Akesson, B. Lind, U. Bjors, A. Schutz and M. Berglund, Environ. Res., 2000, 84, 186-194.

35 M. Yoshida, Tohoku J. Exp. Med., 2002, 196, 79-88.

36 K. Ask, A. Åkesson, M. Berglund and M. Vahter, Environ. Health Perspect., 2002, 110, 523-526.

37 M. Sakamoto, M. Kubota, X. J. Liu, K. Murata, K. Nakai and H. Satoh, Environ. Sci. Technol., 2004, 38, 3860-3863.

38 R. C. Marques, J. G. Dorea, W. R. Bastos, M. de Freitas Rebelo, M. de Freitas Fonseca and O. Malm, Int. J. Hyg. Environ. Health, 2007, 210, 51-60.

39 R. L. Canfield, D. A. Kreher, C. Cornwell and C. R. Henderson, Jr., Child Neuropsychol., 2003, 9, 35-53.

40 A. M. Fletcher, K. H. Gelberg and E. G. Marshall, J. Community Health, 1999, 24, 215-227.

41 J. D. Garcia Diaz and C. Guijarro Herraiz, Med. Clin. (Barc), 1989, 92(795), 32.
42 N. Nashashibi, E. Cardamakis, G. Bolbos and V. Tzingounis, Gynecol. Obstet. Invest., 1999, 48, 158-162.

43 S. Rastogi, K. Nandlike and W. Fenster, J. Perinat. Med., 2007, 35, 492-496.

44 E. Emory, R. Pattillo, E. Archibold, M. Bayorh and F. Sung, Am. J. Obstet. Gynecol., 1999, 181, S2-11.

45 B. P. Lanphear, R. Hornung, J. Khoury, K. Yolton, P. Baghurst, D. C. Bellinger, R. L. Canfield, K. N. Dietrich, R. Bornschein, T. Greene, S. J. Rothenberg, H. L. Needleman, L. Schnaas, G. Wasserman, J. Graziano and R. Roberts, Environ. Health Perspect., 2005, 113, 894-899.

46 C. N. Ong, S. E. Chia, S. C. Foo, H. Y. Ong, M. Tsakot and P. Liouw, Biometals, 1993, 6, 61-66.

47 ATSDR, Toxicological Profile for Manganese, Agency for Toxic Substances and Disease Registry, Atlanta, 2000.

48 O. P. Soldin and M. Aschner, Neurotoxicology, 2007, 28, 951-956.

49 L. Takser, D. Mergler, G. Hellier, J. Sahuquillo and G. Huel, Neurotoxicology, 2003, 24, 667-674.

50 P. J. Kontur and L. D. Fechter, Neurotoxicol Tetratol., 1988, 10, 295-303.

51 D. C. Dorman, M. F. Struve, D. Vitarella, F. L. Byerly, J. Goetz and R. Miller, J. Appl. Toxicol., 2000, 20, 179-187.

52 A. Takeda, T. Akiyama, J. Sawashita and S. Okada, Brain Res., 1994, 640, 341-344.

53 R. G. T. Clarksom, In Toxicology: the basic science of poisons, ed. McGraw-Hill, Editon edn., 2001, vol. 6th.

54 E. Al-Saleh, M. Nandakumaran, M. Al-Shammari, F. Al-Falah and A. Al-Harouny, J. Matern. Fetal Neonatal Med., 2004, 16, 9-14.

55 J. H. Mitchell, F. Nicol, G. J. Beckett and J. R. Arthur, J. Mol. Endocrinol., 1998, 20, 203-210.

56 E. Barany, I. A. Bergdahl, L. E. Bratteby, T. Lundh, G. Samuelson, S. Skerfving and A. Oskarsson, J. Trace Elem Med Biol, 2003, 17, 165-170.

57 A. K. Linberg, A. K. Björnberg, M. Vahter and M. Bergelund, Environ. Res., 2004, 96, 28-33. 